\title{
Memory impairment in the weapon focus effect
}

\author{
Jo SAUNDERS \\ Swansea University, Swansea, Wales
}

\begin{abstract}
Two experiments are reported in which postevent source of misinformation was manipulated within weaponpresent and weapon-absent scenarios. Participants viewed slides depicting either a weapon or a newspaper event and then received either incomplete questioning or a narrative. Both postevent sources contained misleading information about a central and peripheral detail concerning either the weapon or the newspaper scenario. With a modified test in Experiment 1, questioning was found to increase misinformation effects concerning the central item, as compared with a narrative, and more misinformation effects were found for the weapon-peripheral than for the newspaper-peripheral item. In Experiment 2, the participants were more likely to claim to have seen contradictory and additive misinformation about the central item in the slides following questioning, and more contradictory and additive misinformation effects occurred for the weapon-peripheral than for the newspaper-peripheral item. The findings are considered in terms of the effects of both postevent and encoding factors on memory.
\end{abstract}

Many factors influence the direction of a criminal investigation. Physical evidence, such as fingerprints or DNA left at a scene by a careless perpetrator, provides, we would hope, the most compelling evidence for those involved in investigative and judicial processes. Given the advances in the application of technology in the forensic sector, it remains surprising that eyewitness evidence still takes pride of place in directing the course of investigations and prosecutions. The human face of evidence thus remains a potent influencing factor.

One encoding factor that has caught the interest of perceptual and memory researchers is the influence of weapons on how an eyewitness remembers an event. The weapon focus effect refers to the attention directed toward a weapon in a scenario, usually at the expense of other details. Typically, participants in weapon-present conditions display poorer memory for other details surrounding the weapon (i.e., peripheral details), such as the perpetrator holding the weapon, as compared with weapon-absent scenarios (see Pickel, 2007, for a review).

Several accounts have been put forward to explain weapon focus effects on central and peripheral items. Attentional accounts suggest that participants spend more time looking at and, therefore, attending to the weapon than they do other peripheral details. Simply put, memories are not formed or, at least, are considerably weaker where attention does not fall. Such accounts suggest that the perceived dangerousness of weapons leads to high levels of stress and emotion, which affect attentional resources (Easterbrook, 1959).

Weapons may also attract attention due to their unusualness in certain contexts (Kramer, Buckhout, \& Eugenio, 1990; Loftus, Loftus, \& Messo, 1987). For example, although we know that bank robberies occur from time to time, we do not expect someone to draw a weapon when we ourselves are visiting the bank. The presence of a weapon may, therefore, be contextually inappropriate. For example, Pickel (1998) manipulated unusualness and threat but found that only unusualness impacted memory (see also Pickel, Ross, \& Truelove, 2006). This finding suggests that it may be unusualness, rather than threat, that captures our attention. Conversely, when a weapon appears in a contextually appropriate scene (e.g., at a shooting range, carried by a police officer), the weapon focus effect does not emerge (Pickel, 1999).

Unlike encoding factors that cannot be controlled by investigators during eyewitness situations and can be estimated only post hoc, postevent factors can be controlled to a certain degree in an attempt to reduce bias. However, although system variables can be controlled and manipulated in the laboratory, control is less likely in real-world settings, such as the police interview room. Misleading postevent questions, for example, may bias the responses of witnesses to questions. Loftus and colleagues found that participants made more memory errors after being exposed to postevent questions containing misleading information; that is, they were less likely to select the original item from the encoding phase on a recognition test than were participants who had not been misled (Loftus, 2005; Loftus \& Hoffman, 1989; Loftus, Miller, \& Burns, 1978).

One possible influencing factor that may affect the successfulness of introducing misleading information is the source of the misinformation. Studies in which postevent misleading information has been used have tended to embed misinformation in either postevent questioning (PEQ; e.g., Loftus et al., 1978) or postevent narratives (PENs; e.g., Lindsay, 1990). Although both sources have previously produced robust misinformation effects, there 
are reasons to suspect that PEQ may be more successful at misleading participants than are narratives (see Zaragoza \& Lane, 1994). PEQ in misinformation studies can be considered a type of incomplete retrieval practice task. Although retrieval practice is known to facilitate memory for retrieved items (Landauer \& Bjork, 1978; Morris \& Fritz, 2000, 2002), it has recently been found also to have negative consequences for items that are not the focus of retrieval but are drawn from the same category or episode as retrieved items. This impairment in memory for nonretrieved items from episodes is known as retrievalinduced forgetting (see Anderson, 2003, for a review) and is believed to be the product of inhibitory processes that actively inhibit or suppress memory traces (but see C. M. MacLeod, Dodd, Sheard, Wilson, \& Bibi, 2003, for an alternative, noninhibitory account).

Retrieval-induced forgetting has also been found to operate in incomplete PEQ in eyewitness scenarios in which participants are questioned about a subset of details concerning an event. Shaw, Bjork, and Handal (1995) found that retrieval-induced forgetting operates in episodic memory for an eyewitness event, and M. D. MacLeod (2002) has found that it occurs for descriptor information concerning the appearance of a suspect. Thus, both of these studies indicate not only that incomplete PEQ is a retrieval task, but also that incomplete questioning can lead to poorer memory for nonquestioned items from a questioned event than if participants were not questioned at all.

Incomplete PEQ has also been found to have an additional negative consequence for memory. Previous work has indicated that PEQ increases susceptibility to misleading information (M. D. MacLeod \& Saunders, 2005, 2006; Saunders \& MacLeod, 2002). Of particular relevance to the present experiments is work by M. D. MacLeod and Anderson (2008), who have examined whether the typical PEQ used in misinformation studies leads to active forgetting of the original item. Specifically, PEQ in misinformation studies can be considered a form of selective retrieval practice whereby the removal of the original item during PEQ may lead to unintentional forgetting of the original item. These retrieval-induced forgetting effects are initiated by the incomplete retrieval of other members of a category (e.g., eyewitness scenarios). Thus, although PEQ requires participants to remember some details of an event, the very nature of misinformation studies means that the original item is not the focus of a retrieval attempt during questioning. With the PEQ typically used in misinformation studies, M. D. MacLeod and Anderson have found that it initiates retrieval-induced forgetting, resulting in suppression of the original item and increased reporting of misleading information (see also M. D. MacLeod \& Saunders, 2006, 2008, for further information about the vulnerability of Loftus's paradigm in initiating retrieval-induced forgetting).

Although many misinformation studies have utilized PEQ as the source of misleading information, many studies have not but, rather, have used PENs that act as written descriptions of the event (e.g., Echterhoff, Groll, \& Hirst, 2007; Lindsay \& Johnson, 1989). Noncritical details from the event are, thus, re-presented, rather than requiring the active retrieval of these items. Recent work on retrieval- induced forgetting has suggested that re-presentation is less likely to lead to retrieval-induced forgetting of nonretrieved items (Anderson, E. L. Bjork, \& R. A. Bjork, 2000). Failure to produce retrieval-induced forgetting through representation may be due to the presentation of cue-related information that is sufficient to allow for the specific retrieval of the to-be-remembered item. Thus, re-presented items may be less likely to compete for retrieval with nonpresented items about an event. Conversely, PEQ may increase competition between these items in the absence of sufficient cue-related information. Given that retrievalinduced forgetting has been found to facilitate misinformation effects (M. D. MacLeod \& Saunders, 2005; Saunders $\&$ MacLeod, 2002), PENs may, therefore, not be as successful a vehicle for misinformation effects as PEQ.

One way to compare questioning and narratives is to examine their ability to mislead witnesses about central items in weapon scenarios. Since central items are believed to receive greater attention and, thus, produce a stronger memory in weapon-present, as compared with weapon-absent, scenarios, as well as in comparison with peripheral items, it could be quite difficult to mislead witnesses about a central item (Wright \& Stroud, 1998). Research on retrieval-induced forgetting, however, indicates that it is the strongest of memories that may be the most vulnerable to forgetting. For example, Anderson, R. A. Bjork, and E. L. Bjork (1994) found that retrieval-induced forgetting occurred for items that strongly competed with a target memory, but not for weak competitors, and Racsmany and Conway (2006) found that moderate-to-strong items were also vulnerable to retrieval-induced forgetting. Anderson and colleagues accounted for this finding by suggesting that strong competitors are more likely to compete and interfere with the retrieval of target memories and, thus, are likely to be inhibited in an attempt to resolve this unwanted competition. Weak items, on the other hand, are less likely to compete and interfere with the retrieval process, because of their weak status.

The weapon focus effect also provides an ideal avenue for investigating strength effects in a more applied setting. Strength effects have been found only in word lists (Anderson et al., 1994), whereas no effect was found by Hauer, Wessel, Merckelbach, Roefs, and Dalgleish (2007), who failed to find retrieval-induced forgetting for central details with emotional materials, although this may, in part, be due to as yet unknown differences between what is considered a strong exemplar and what is considered a central detail, as well as to differences in the emotional and arousal effects of pictures and words. The strength of items and details within an event, however, can be examined with episodic materials by manipulating the presence or absence of a weapon. The presence of a weapon is likely to strengthen central details and draw attention away from peripheral details. Similarly, in nonweapon events, central details are expected to be stronger than peripheral details, although not to the same extent as for scenarios with weapons. Thus, central weapon items are likely to be strongest, followed by nonweapon central details and nonweapon peripheral details; and, finally, weapon peripheral details are likely to be the weakest item type. 
Given that the type of PEQ used in misinformation studies is sufficient to lead to retrieval-induced forgetting of the original item (M. D. MacLeod \& Anderson, 2008) and that the work of Anderson et al. (1994) has suggested that strong items are more vulnerable to retrieval-induced forgetting, it may be possible to mislead participants about central items in weapon conditions, despite the assumed strength of the memory. One way to test this assumption is to compare the ability of PEQ, which is known to initiate retrieval-induced forgetting and facilitate misinformation effects, with that of PENs, which may be considered a form of re-presentation that is less likely to lead to retrieval-induced forgetting.

Experiment 1, therefore, examined the impact that misleading information would have on memory for an event containing a weapon or a newspaper. It was predicted that source of misinformation would have an effect only on reporting of the original item for the central item. Since the central items in weapon and newspaper events are strong items, they are most likely to be subject to retrievalinduced forgetting, but only when misinformation appears in PEQ. Since PENs are more passive tasks that re-present information, they are unlikely to initiate retrieval-induced forgetting, and therefore, misinformation is less likely to affect performance. Conversely, since the peripheral items from the weapon and newspaper scenarios are weaker items, PEQ is unlikely to initiate retrieval-induced forgetting, and therefore, no differences would be expected between questioning and narrative conditions in terms of reporting of the original item.

\section{EXPERIMENT 1 Central and Peripheral Misinformation in Weapon-Present and Weapon-Absent Scenarios}

Method
Participants and Design
Two hundred undergraduate students from the University of
Wales, Swansea participated in this study in exchange for course
credit or $£ 3$. The experiment had a 2 (scenario: weapon or paper) $\times$
2 (source: questioning [PEQ] or narrative [PEN]) $\times 2$ (detail: central
or peripheral) mixed design with repeated measures on the latter fac-
tor. Each condition contained 50 participants.

\section{Materials}

Central and peripheral details were identified in a pilot study. A slide show consisting of five slides was presented to 34 participants, of which half received the slides containing the weapon and half received the slides containing the newspaper in place of a weapon. In the weapon condition, a man is seen approaching a woman before producing a knife, grabbing her shoulder bag, and leaving the scene. The slide with the knife was the third slide and showed the man pointing the knife into the camera in a close-up view with the knife appearing in the center of the slide. The participants in the newspaper condition saw the same event, except that the man had a folded newspaper in his hand. Each slide was shown for $5 \mathrm{sec}$ and was presented on a projector screen.

After viewing the slides, the participants were asked to write down what they could remember from the slides. The five most recalled items were used as central items, of which the proportion of participants who recalled these items was .87 in the weapon condition and .59 in the newspaper condition. The five least recalled items were used as peripheral items, of which the proportion of participants who recalled these items was .16 in the weapon condi- tion and .33 in the newspaper condition. A $t$ test analysis confirmed that the central items were remembered more often in the weapon condition than in the newspaper condition $[t(32)=4.87, p<.01]$ and that the peripheral items were remembered more poorly in the weapon than in the newspaper condition $[t(32)=-2.55, p<.05]$. All the participants reported the knife in the weapon condition, with the majority reporting that it had a checked handle $(M=.88)$, and so this feature of the knife was selected to be misleading information for the experiment. Likewise, all the participants reported the newspaper in the newspaper condition, with the majority also reporting the name of the paper $(M=.65)$, and so the paper name was selected as an item to mislead the participants about. Although the newspaper central item was not as strong as the weapon central item, it was still remembered well and could be considered moderate to strong in strength. Previous research has indicated that moderate to strong items are also vulnerable to retrieval-induced forgetting (Racsmany \& Conway, 2006).

In addition, the handle of the knife and the name of the newspaper could be considered details of a central item. Previous research examining the weapon focus effect had tended to look at memory for central items rather than for details of an item (Pickel et al., 2006). However, in a police investigation, an eyewitness might first be asked whether there was a weapon and then might be asked to describe that weapon. Since the pilot work indicated that the details were remembered well, they could be considered central details of central items.

Conversely, fewer participants remembered the peripheral feature of a plastic bag lying on the ground (weapon, $M=.24$; newspaper, $M=.47$ ), and so this item was selected as a peripheral item about which misleading information would be introduced in the experiment. Thus, the findings from the pilot study indicated that participants encoded and remembered features of the weapon and newspaper and were less likely to encode and remember features of the peripheral item.

It should be noted, however, that memorability of items is not typically used as a measure of centrality. Central items usually involve thematic details and central characters of a scenario, whereas peripheral items concern background details. Although a measure of memorability has been taken, the highly memorable items can also be considered to be thematically relevant or to refer to central characters (i.e., checked-handled knife [misinformation]; Coffee Break newspaper [misinformation]; man's hooded navy top; woman's black t-shirt; man's "motorcycle" hat; rainy day; gray handbag), whereas the peripheral items refer to background details (i.e., woman's silver bracelet; plastic carrier bag [misinformation]; green garage door; green parked car; white writing on garage door; number of garage doors).

\section{Procedure}

The participants viewed the slide show from the pilot study, with half of the participants viewing the weapon scenario (see Figure 1) and half viewing the newspaper scenario (see Figure 2). Each slide was shown for $5 \mathrm{sec}$ and was presented on a projector screen. After viewing the slide sequence, the participants were presented with either PEQ about the event or a PEN describing the event. No information was given to the participants about the possible source of the PEQ or PEN (e.g., police questions or witness/police statements). In the PEQ conditions, 12 questions were presented. Five questions referred to peripheral details, and 5 to central details. Two additional questions contained misleading information. One question presented misleading information about a central detail that differed across weapon and newspaper conditions (i.e., "What color was the Daily News headline?" referred to the paper Coffee Break in the newspaper condition, and "What hand was the man holding the knife with the striped handle?" referred to the knife with the checked handle in the weapon condition). One question also presented misleading information about a peripheral detail (i.e., "What brand of drinks can is lying on the ground?" referred to a plastic carrier bag) and was used in both the weapon and the newspaper conditions. For the PEN conditions, a written description of the event was presented to the participants. The five central 


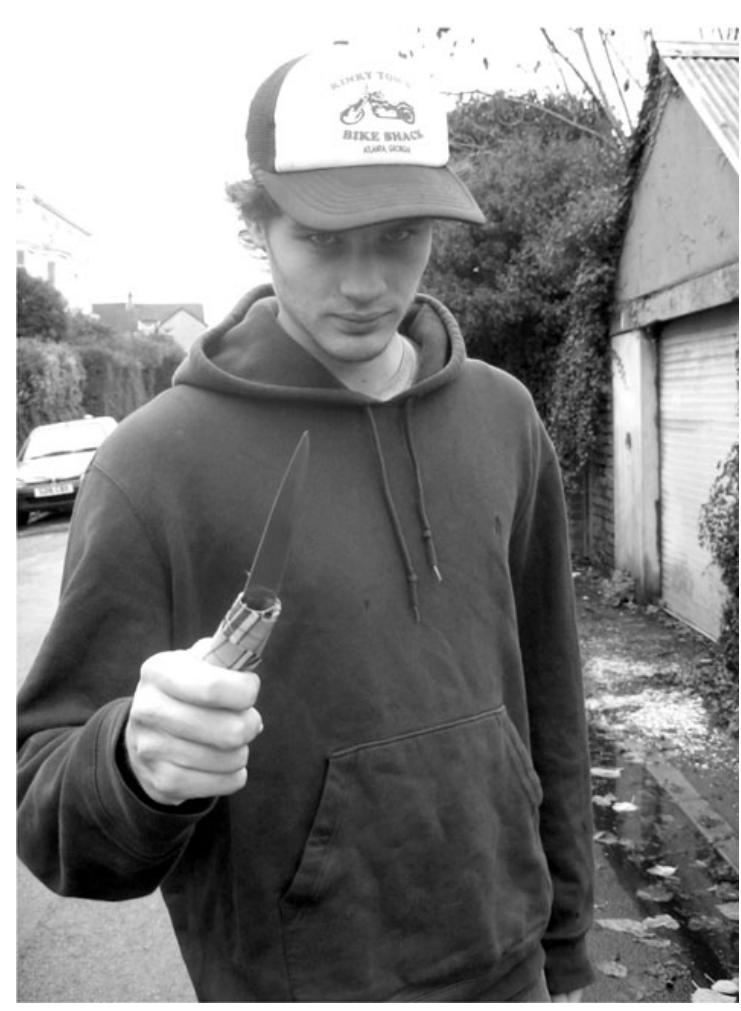

Figure 1. Black-and-white slide with knife from the weapon condition.

and five peripheral items were mentioned, and each participant was exposed to either a central weapon (i.e., "The man was holding a striped handled knife in his right hand that was approximately six inches in length") or a central newspaper misinformation item (i.e., "The man was holding a copy of the Daily News in his right hand and the headline was typed in red and yellow"), as well as a peripheral misleading item (i.e., "A drinks can could be seen lying on the ground"). Since temporal order of cues can be a contributing factor to misinformation effects (Bekerian \& Bowers, 1983), and PENs typically follow a chronological order in their descriptions of an event (Lindsay, 1990; Lindsay \& Johnson, 1989), both the order of questions and the order of events described in the PEN in Experiment 1 followed a sequential chronological order. Although questions were, therefore, not randomized, sequential order was maintained across postevent sources.

After completing the postevent phase, the participants were presented with a modified recognition memory task consisting of 12 multiple-choice questions. Each question contained three possible answers (i.e., original item plus two new items), and the participants were instructed to circle the item that they believed was correct. The misleading item was not a choice (McCloskey \& Zaragoza, 1985). Of these 12 questions, 5 questions referred to central items, and 5 to peripheral items. One question also referred to the central misleading item, and one referred to the peripheral misleading item. The only question that differed across conditions was the central misleading question, which referred to the knife in the weapon condition and to the folded newspaper in the newspaper condition. The question number of the misleading items was randomized across participants, and the order of questions referring to nonmisleading items was randomized. After completing the recognition test, the participants were debriefed, thanked, and dismissed.

\section{Results}

\section{Selection of the Original Item}

With the modified recognition test, misinformation effects are measured by the proportion of participants who correctly chose the original item, as compared with those who chose a new item (McCloskey \& Zaragoza, 1985). Since the dependent variable (i.e., selection of original item or not) and the independent variables of postevent source, scenario, and item type (i.e., central or peripheral) are dichotomous, frequencies of selecting the original item were analyzed using log linear analysis. Since the original central and peripheral items were within-subjects variables, separate log linear analyses were conducted on each item.

First, frequency of reporting weapon-central and newspaper-central details following PEQ and PENs was analyzed using log linear analysis. PEQ was found to decrease performance for all central details (weapon central, $M=.48$; newspaper central, $M=.54$ ), in comparison with PENs (weapon central, $M=.72$; newspaper central, $M=.66)[\chi(1)=6.80, p<.01$; see Table 1]. Type of scenario was not found to significantly affect reporting of central details $[\chi(1)=.00$, n.s. $]$, and scenario and source were not found to interact $[\chi(1)=.00$, n.s.].

Frequencies of reporting weapon-peripheral and newspaper-peripheral details following PEQ and PEN

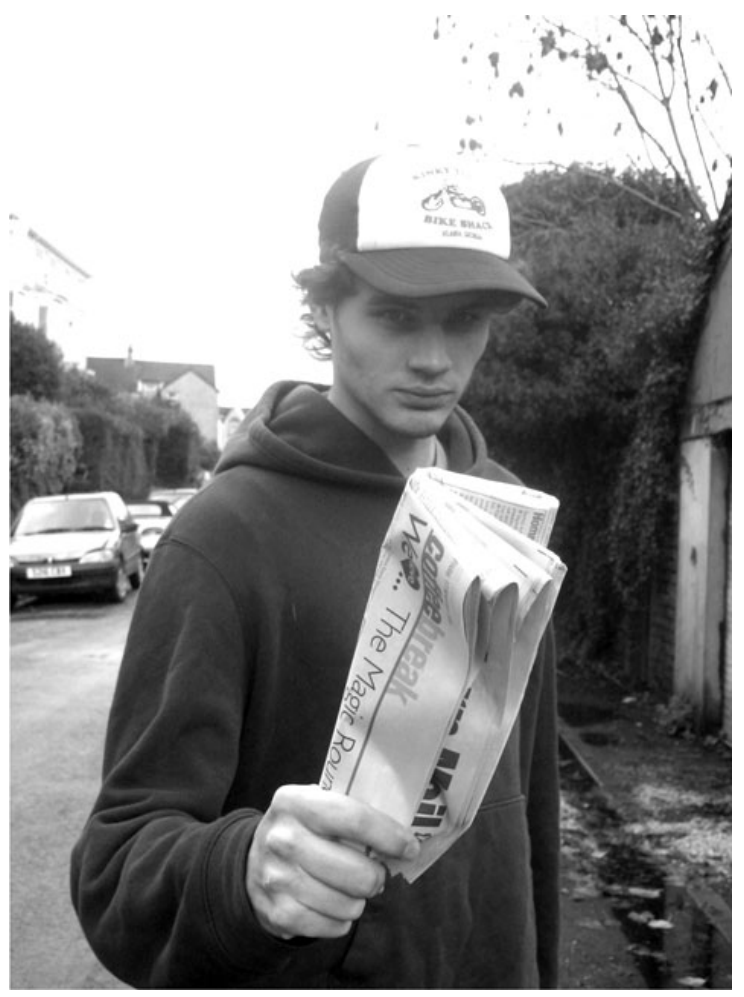

Figure 2. Black-and-white slide with newspaper from the newspaper condition. 
Table 1

Proportion of Participants Selecting the Original Item at Test As a Function of Scenario and Source of Misinformation in Experiment 1

\begin{tabular}{clcc}
\hline \multirow{2}{*}{ Source } & Scenario & \multicolumn{2}{c}{ Item Type } \\
\cline { 3 - 4 } Questions & Weapon & .48 & Peripheral \\
\hline \multirow{2}{*}{ Narrative } & Newspaper & .54 & .20 \\
& Weapon & .72 & .18 \\
& Newspaper & .66 & .58 \\
\hline
\end{tabular}

Note- "Source" refers to postevent source of misinformation (i.e., postevent questioning or postevent narrative). "Scenario" refers to the slides that the participants viewed (i.e., weapon or newspaper). All the participants were misled over a central and a peripheral detail from the event that they viewed.

were analyzed in a second log linear analysis. Scenario was found to affect the reporting of the original detail, with the original peripheral detail reported more in the newspaper scenario (PEQ, $M=.50 ; \mathrm{PEN}, M=.58$ ) than in the weapon scenario (PEQ, $M=.20$; PEN, $M=.18$ ) $[\chi(1)=35.90, p<.001]$. No effect was found for source on reporting of the original detail, with similar performance for weapon-peripheral and newspaper-peripheral details following PEQ (weapon, $M=.20$; newspaper, $M=.50$ ) and PEN (weapon, $M=.18$; newspaper, $M=$ .58) $[\chi(1)=2.22$, n.s. $]$, and source and scenario were not found to interact $[\chi(1)=1.76$, n.s.].

\section{Memory for Noncritical Items}

Memory for central and peripheral noncritical details was also examined. Independent $t$ tests revealed that central details were remembered more in the weapon condition $(M=.75)$ than in the newspaper condition $(M=.62)$ $[t(198)=4.57, p<.001]$ and that peripheral details were remembered more poorly in the weapon condition $(M=$ $.35)$ than in the newspaper condition $(M=.53)[t(198)=$ $-6.18, p<.001$; see Table 2]. Thus, the typical weapon focus effect of enhanced memory for central items at the expense of peripheral details in weapon scenarios was replicated (Christianson, 1992).

\section{Discussion}

PEQ was found to increase susceptibility to misinformation effects for weapon-central and newspaper-central details, in comparison with a PEN. The reduction in the reporting of central details in the questioning condition may be due to the initiation of retrieval-induced forgetting. Since the weapon-central detail can be considered strong and the newspaper-central detail can be considered moderate to strong, the very strength of these details may have made them vulnerable to retrieval-induced forgetting. Conversely, due to the weaker encoding of the weapon-peripheral and newspaper-peripheral details, these details are insufficiently strong to initiate retrievalinduced forgetting, and thus, no differences were found for source of misinformation. Given that the participants were as likely to choose the original detail irrespective of whether they had been questioned or had received a nar- rative, it suggests that the primary source of suggestibility for peripheral detail is encoding factors.

Misinformation effects were evident on the central detail following PEQ and on the peripheral detail irrespective of postevent task, using a modified forced-choice recognition task. Although the modified test provides evidence of genuine memory impairment, it does not inform us regarding the quality of the memorial experience. This memory task does not indicate whether participants believe that they saw the misleading detail in the original slide sequence. If participants believe that they saw an item that they only were questioned or read about, this might provide additional evidence that genuine memory impairment has occurred. Likewise, previous research linking retrieval-induced forgetting with the misinformation effect has not examined whether retrieval-induced forgetting affects the quality of the experience when misinformation is remembered. Thus, it is unclear whether retrieval-induced forgetting facilitates remembering the misinformation from the slide sequence. In Experiment 2, therefore, a yes/no recognition test was used that specifically asked participants whether they had seen each individual item, including the misleading item, in the slide sequence.

In previous studies in which participants have been asked whether they saw the misleading item in the original slide or video sequence, source-monitoring tests that examined whether they remembered seeing a supplementary item have typically been used (e.g., Lindsay \& Johnson, 1989; Zaragoza \& Lane, 1994). Supplementary misinformation is additive, rather than specifically contradicting a previously studied detail. With this in mind, Experiment 2 manipulated the type of misleading information. Misinformation was, therefore, contradictory or additive (i.e., was a supplementary item).

Since PEQ utilizes the active processes of retrieval that have previously been found to facilitate the reporting of misinformation, it was predicted that PEQ would facilitate contradictory and additive misinformation directed at the weapon-central and newspaper-central details. Since PEN utilizes more passive re-presentation processes, PEN was expected to lead to fewer misinformation effects, in comparison with PEQ, on central details. Conversely, peripheral details in weapon and newspaper scenarios are weaker items and, thus, PEQ was unlikely to initiate retrieval-induced forgetting. Therefore, no differences were expected in level-of-misinformation effects for contradictory or additive items between PEQ and PEN.

\section{EXPERIMENT 2 \\ Contradictory and Additive Misinformation in the Weapon Focus Effect}

\section{Method}

\section{Participants and Design}

Two hundred forty undergraduate students from the University of Wales, Swansea participated in this experiment in exchange for course credit or $£ 3$. The experiment had a 2 (scenario: weapon or paper) $\times 2$ (source: questioning or narrative) $\times 2$ (detail: central or peripheral) $\times 2$ (misinformation: contradictory or additive) mixed 
Table 2

Memory Performance for Noncritical Items in Experiment 1

\begin{tabular}{cccccc}
\hline & \multicolumn{3}{c}{ Item Type } \\
\cline { 2 - 3 } \cline { 5 - 6 } Scenario & \multicolumn{2}{c}{ Central } & & \multicolumn{2}{c}{ Peripheral } \\
\cline { 2 - 5 } \cline { 3 - 6 } & $M$ & $S D$ & & $M$ & $S D$ \\
\hline Weapon & .75 & .19 & .35 & .22 \\
Newspaper & .62 & .23 & .53 & .19 \\
\hline
\end{tabular}

design with repeated measures on the latter two factors. Each condition contained 60 participants.

\section{Materials}

The same materials as those in Experiment 1 were used, with the exception of the type of misleading items during the postevent phases.

Type of misinformation. Whereas Experiment 1 examined the effects of contradictory misleading information on memory, Experiment 2 used both contradictory and additive misinformation. Contradictory misinformation is typically used in traditional misinformation paradigms and tends to target an item from the original event (e.g., Loftus et al., 1978), whereas additive misinformation is typically used in source-monitoring (e.g., Zaragoza \& Lane, 1994) or reversed suggestibility studies (e.g., Lindsay \& Johnson, 1989) and concerns an additional item that could have been present but was not (Frost, 2000). Additive and contradictory misinformation items were chosen for weapon-central, newspaper-central, weapon-peripheral, and newspaper-peripheral details. There were two possible versions of each misleading item, and selection of the misleading item was counterbalanced across participants. Each participant received one central contradictory and one additive misleading detail, and one peripheral contradictory and one additive misleading detail. Weapon-central contradictory details referred to the knife's handle (PEQ, "What hand was the man holding the knife with the striped [or green] handle?"; PEN, "The man was holding a striped [or green] handled knife in his right hand that was approximately six inches in length"), and newspaper-central contradictory details referred to the newspaper (PEQ, "What color was the Daily News [or Welsh Post] headline?"; PEN, "The man was holding a copy of the Daily News [or Welsh Post] in his right hand and the headline was typed in red and yellow"). The peripheral misleading contradictory detail referred to a plastic carrier bag lying on the ground (PEQ, "How many holes where in the Sainsbury's [or Marks \& Spencer's] carrier bag lying on the ground?"; PEN, "A torn Sainsbury's [or Marks \& Spencer's] carrier bag could be seen lying on the ground"), and was used in both the weapon and the newspaper scenarios.

To ensure that central additive misinformation was directed at an object as close to the central detail as possible without its actually becoming a contradictory item, central additive misinformation referred to the hand in which the suspect was holding either the knife or the newspaper. For both weapon and newspaper scenarios, central additive misinformation was schema consistent (Rojahn \& Pettigrew, 1992) and concerned the suspect's either wearing a wedding ring (PEQ, "What type of gold was the ring that the man was wearing?"; PEN, "He was wearing a white gold ring on his ring finger") or wearing a Band-Aid plaster on the back of his hand (PEQ, "What color was the plaster that the man had on the back of his hand?"; PEN, "A beige plaster could be seen on the back of his hand"). Additive peripheral details referred to an additional detail in the background of the slides (PEQ, "What brand of drinks can [or crisp packet] is lying on the ground?"; PEN, "A drinks can [or crisp packet $]$ could be seen lying on the ground") and was used in both the weapon and the newspaper conditions. Only one central additive and one peripheral additive detail were presented to each participant and were counterbalanced across participants.

\section{Procedure}

The same procedure as that in Experiment 1 was used, with the exception of the addition of contradictory and additive misinformation and the final recognition test.

The study phase was identical to that in Experiment 1, with participants viewing either the weapon or the newspaper scenario and then being presented with either PEQ or a postevent narrative. The PEQ and PEN were identical to those in Experiment 1, except that the participants received one central-contradictory and one centraladditive misleading detail, as well as one peripheral-contradictory and one peripheral-additive misleading detail. The participants were also not given any information concerning the possible source of the PEQ and PEN.

After completing the postevent phase, the participants were presented with a yes/no recognition memory task that required them to indicate whether a series of items had been present in the slide sequence. The test contained 26 items in total, including the central and peripheral original items, their corresponding contradictory misleading items, central and peripheral additive items, noncritical items, and new items. Each item was presented individually following the question, "In the slides? Yes? No?" and the participants were asked to circle a response (Lindsay \& Johnson, 1989). After completing the recognition test, the participants were debriefed, thanked, and dismissed.

\section{Results}

Since detail type (i.e., central and peripheral) and misinformation type (i.e., contradictory and additive) are within-subjects variables, separate log linear analyses were conducted on each item type.

\section{Selection of the Original Item}

First, frequency of reporting weapon-central and newspaper-central details following PEQ and PENs was analyzed using log linear analysis. PEQ was found to decrease performance for all central details (weapon central, $M=.47$; newspaper central, $M=.52$ ), in comparison with PEN (weapon central, $M=.73$; newspaper central, $M=.65)[\chi(1)=17.42, p<.001$; see Table 3$]$. Type of scenario was not found to significantly affect reporting of central details $[\chi(1)=0.61$, n.s. $]$, and scenario and source were not found to interact $[\chi(1)=0.77, \mathrm{n} . \mathrm{s}$. $]$.

Frequency of reporting weapon-peripheral and newspaper-peripheral details following PEQ and PEN was analyzed in a second log linear analysis. Scenario was found to affect the reporting of the original detail, with the original peripheral detail reported more often in the news-

Table 3

Proportion of Participants Indicating That the Original Item Was Viewed in the Slides As a Function of Scenario and Postevent Source in Experiment 2

\begin{tabular}{clcc}
\hline \multirow{2}{*}{ Source } & Scenario & \multicolumn{2}{c}{ Original Item Type } \\
\cline { 3 - 4 } Questions & Central & Peripheral \\
\hline \multirow{2}{*}{ Narrative } & Newspaper & .47 & .22 \\
& Weapon & .73 & .53 \\
& Newspaper & .65 & .20 \\
&
\end{tabular}

Note- "Source" refers to postevent source of misinformation (i.e., postevent questioning or postevent narrative). "Scenario" refers to the slides that the participants viewed (i.e., weapon or newspaper). 
Table 4

Proportion of Participants Indicating That the Misleading Item Was Viewed in the Slides As a Function of Scenario, Source of Misinformation, and Item Type (Contradictory, Additive, Central, or Peripheral) in Experiment 2

\begin{tabular}{clccccc}
\hline \multirow{2}{*}{ Source } & & \multicolumn{4}{c}{ Misinformation Type } \\
\cline { 3 - 4 } \cline { 6 - 7 } \cline { 6 - 7 } Questions & Scenario & Contradictory & Additive & Contradictory & Additive \\
\cline { 3 - 6 } Narrative & Neapon & .70 & .63 & & .75 & .87 \\
& Newspaper & .57 & .53 & & .47 & .67 \\
& Weapon & .40 & .37 & & .72 & .83 \\
& Newspaper & .37 & .42 & & .50 & .60 \\
\hline
\end{tabular}

Note- "Source" refers to postevent source of misinformation (i.e., postevent questioning or postevent narrative). "Scenario" refers to the slides that the participants viewed (i.e., weapon or newspaper). All the participants were misled over a central and a peripheral detail from the event that they viewed. "Contradictory" misinformation refers to postevent information that contradicted a previously studied item from the slide sequence. "Additive" misinformation refers to supplementary postevent information.

paper scenario (PEQ $M=.53 ; \mathrm{PEN} M=.60)$ than in the weapon scenario (PEQ, $M=.22 ; \mathrm{PEN}, M=.20)[\chi(1)=$ $33.45, p<.001]$. No effect was found for source on reporting of the original detail, with similar performance for weapon-peripheral and newspaper-peripheral details following PEQ and PEN $[\chi(1)=0.18$, n.s.], and source and scenario were not found to interact $[\chi(1)=0.03$, n.s. $]$. Thus, reporting of the original central detail from weapon and newspaper scenarios is affected by the type of postevent task engaged in but does not affect reporting of the original peripheral detail. Conversely, the source of the peripheral original detail affects its reporting, with the newspaper-peripheral detail recognized more often than the weapon-peripheral detail.

\section{Selection of the Misleading Item}

Contradictory misinformation. Log linear analysis also indicated that PEQ increased the reporting of the contradictory misinformation about central details from weapon and newspaper conditions (weapon central, $M=$ .70; newspaper central, $M=.57$ ), as compared with PEN (weapon central, $M=.40$; newspaper central, $M=.37$ ) $[\chi(1)=15.28, p<.001 ;$ see Table 4]. Type of scenario was not found to significantly affect reporting of central details $[\chi(1)=1.78$, n.s.], and scenario and source were not found to interact $[\chi(1)=0.11$, n.s. $]$. Conversely, postevent source of misinformation did not affect the reporting of contradictory misinformation about a peripheral detail from the weapon or newspaper scenarios $[\chi(1)=$ 0.00, n.s.]. Type of scenario did, however, affect reporting of misinformation (weapon peripheral, PEQ, $M=.75$, and PEN, $M=.72$; newspaper peripheral, PEQ, $M=.47$, and PEN, $M=.50)[\chi(1)=15.95$, n.s. $]$, and a source $\times$ scenario interaction was not detected $[\chi(1)=0.01$, n.s. $]$.

Additive misinformation. PEQ was also found to increase the reporting of the central additive misinformation detail from weapon and newspaper conditions (weapon central, $M=.63$; newspaper central, $M=.53$ ), as compared with PEN (weapon central, $M=.37$; newspaper central, $M=.42)[\chi(1)=8.83, p<.01]$, but not of the additive peripheral detail (PEQ, weapon, $M=.87$, and newspaper, $M=.67$; PEN, weapon, $M=.83$, and news- paper, $M=.60)[\chi(1)=0.84$, n.s.; see Table 4]. Type of scenario was not significant for the central additive item $[\chi(1)=0.16$, n.s. $]$ but was significant for the peripheral additive detail $[\chi(1)=15.11, p<.001]$. The source $\times$ scenario interaction was not significant for the central $[\chi(1)=0.01$, n.s. $]$ or peripheral $[\chi(1)=0.05$, n.s. $]$ detail. Thus, PEQ affects only the reporting of the central additive misinformation detail, whereas type of scenario affects only the reporting of the peripheral additive misleading detail.

\section{Memory for Noncritical Items}

Independent $t$ tests revealed that central noncritical details were remembered more often in the weapon condition $(M=.78)$ than in the newspaper condition $(M=.66)$ $[t(198)=4.02, p<.001]$, and peripheral noncritical details were remembered more poorly in the weapon condition $(M=.36)$ than in the newspaper condition $(M=.54)$ $[t(198)=-5.67, p<.001$; see Table 5], indicating the presence of a weapon focus effect for noncritical details.

\section{GENERAL DISCUSSION}

Previous research has indicated that when a weapon is present in a scenario, individuals are more likely to focus their attention on central details at the expense of peripheral details (e.g., Loftus et al., 1987; Pickel, 2007; Pickel et al., 2006). Although encoding factors play an important role in the weapon focus effect, the present experiments also suggest a role for postevent factors. Specifically, the type of task used for reviewing memory for weaponpresent and weapon-absent scenarios affects how an event

Table 5

Memory Performance for Noncritical Items in Experiment 2

\begin{tabular}{cccccc}
\hline & \multicolumn{4}{c}{ Item Type } \\
\cline { 2 - 3 } \cline { 5 - 5 } Scenario & \multicolumn{2}{c}{ Central } & & \multicolumn{2}{c}{ Peripheral } \\
\cline { 2 - 5 } \cline { 5 - 6 } & $M$ & $S D$ & & $M$ & $S D$ \\
\hline Weapon & .78 & .19 & .36 & .23 \\
Newspaper & .66 & .22 & .54 & .22 \\
\hline
\end{tabular}

Note-New items, $M=.09(S D=.10)$. 
is remembered. Whereas some information may become harder to remember (e.g., weapon-central and newspapercentral original items) due to PEQ, other information may become easier to remember (e.g., contradictory and additive misinformation concerning weapon-central and newspaper-central items).

The findings from the two experiments suggest that postevent factors can influence the weapon focus effect. Questioning was found to decrease reporting of the original detail in weapon-central and newspaper-central items, in comparison with a narrative, as well as promote misinformation effects with both contradictory and additive misleading information. This link between PEQ and reporting of the original and misleading details suggests that the ability to remember the original detail is an important boundary condition for the misinformation effect. Conversely, source of misinformation had little effect on memory for the peripheral details in weapon and newspaper scenarios; that is, no differences were found between PEQ and PEN conditions for the peripheral details.

This pattern suggests two factors that influence the misinformation effect in weapon-present and weapon-absent scenarios: the type of postevent review that participants engage in and the encoding strength of the original item. Questioning appears to be a more effective vehicle for introducing both contradictory and additive misinformation for the weapon-central and newspaper-central items, as compared with a narrative. On the other hand, the source of the misinformation has little effect on the success of misleading participants about the weapon-peripheral and newspaper-peripheral items. For these peripheral items, the scenario that they were drawn from appears to play a more prominent role in initiating misinformation effects. Specifically, the original peripheral detail was less likely to be remembered in weapon than in newspaper scenarios, and this was reflected in higher misinformation effects for the weapon detail.

The type of postevent review that participants engage in may be an important boundary condition for misinformation effects. In order to answer a question, it requires the initiation of retrieval processes in order to recollect and reconstruct a scenario. Misinformation may become incorporated into the memory of the original event during retrieval and reconstruction (Zaragoza \& Lane, 1994). Reading a postevent narrative, on the other hand, is a less active process that does not necessarily require retrieval and reconstructive memory processes to be initiated. Thus, the initiation of active processes at the time of misinformation exposure appears to be a prerequisite for misinformation effects to occur.

Zaragoza and Lane (1994) obtained a similar finding using source-monitoring tests with additive misinformation. Participants were more likely to state that they saw, or saw and read, additive misinformation if the misleading information was in a question rather than in a narrative. Zaragoza and Lane suggested that it is the reconstructive memory processes that operate at the time of misinformation exposure that leave participants vulnerable to making source misattribution errors concerning additive misinformation.
Although the reconstructive account of questioning explains Zaragoza and Lane's (1994) findings, it does not fully explain the present findings. If the reconstructive nature of questioning by itself is sufficient to induce vulnerability to misinformation, the difference between questioning and narrative conditions should have been significant for the central and peripheral details in weapon and newspaper scenarios. The effect of questioning, however, was present only for the central detail; that is, selection of the original detail was lower, and selection of additive and contradictory misinformation was higher, following questioning than following the narrative. Conversely, reporting of the original peripheral detail and selection of peripheral misinformation was affected by scenario rather than by source. Thus, questioning may affect susceptibility to misinformation, but only when the item participants are being misled about is a central detail.

One feature of the reconstructive account that may have been overlooked is the initial strength of the original detail. Pilot work conducted in the present experiments indicated that the detail deemed to be central was remembered well, whereas the item deemed to be peripheral was remembered less well. Since questioning affects only the central detail's vulnerability to misinformation, it suggests that the initial strength of the original detail prior to questioning is an important boundary condition for misinformation effects. A retrieval-based account that may be able to explain the present pattern of findings is that of retrievalinduced forgetting, which refers to the forgetting of information in response to a retrieval attempt. When a cue is presented, it may activate many exemplars in memory: the desired memory plus other similar but unwanted memories. Retrieval-induced forgetting has been proposed as a solution to this problem, in that it reduces the retrievability of competing memories so that the desired memory may be retrieved quickly and efficiently (Anderson, 2003).

Strong items in memory, such as central detail in a visual scene or good exemplars of a category, may also be particularly vulnerable to retrieval-induced forgetting. This may be because strong items are more likely to disrupt retrieval of a target memory, whereas weaker items are less able to interfere. To prevent such interference, strong memories are more likely to be suppressed than weaker memories. A similar pattern can be observed in the present experiments for the low reporting of the original central item in the weapon and newspaper scenarios following questioning, but not following the narrative. Likewise, no differences were found between questioning and the narrative for the weaker and less memorable peripheral item. Thus, since the original central item is more likely to be forgotten following questioning than following the narrative, it may be suggested that the central item may be unavailable for selection due to retrieval-induced forgetting. Conversely, since no differences were found between PEQ and the PEN for the peripheral detail, it may be suggested that this item is too weak to initiate retrievalinduced forgetting.

The reconstructive account also does not specify how misinformation comes to be reported in place of an original item. Conversely, retrieval-induced forgetting sug- 
gests that it is the incomplete nature of questioning that facilitates misinformation effects. For example, the critical question asked by Loftus et al. (1978), "Did another car pass the red Datsun while it was stopped at the Stop sign?" queries the possibility of a second car rather than the type of road sign; that is, the original item is not the focus of the retrieval attempt. Since the original item is not itself queried about, it may be subject to retrieval-induced forgetting. Since retrieval-induced forgetting decreases the availability of an item in memory, it makes it easier to mislead a participant about a forgotten item.

The availability of the original central detail also affected the reporting of misinformation. Consistent with previous research demonstrating that retrieval-induced forgetting can be an important boundary condition for the misinformation effect (M. D. MacLeod \& Saunders, 2005; Saunders \& MacLeod, 2002), misinformation was more likely to be reported as having been seen in the slides when the original item had been forgotten. In addition, forgetting of the original detail was most likely to occur when the participants had engaged in the retrieval-based PEQ. The present findings, therefore, suggest that when participants inspect their memory for an event, they may be less likely to locate the original information and more likely to find the misinformation after engaging in PEQ than after reviewing the same information in a narrative.

Although PEQ and retrieval-induced forgetting had less of an effect on the peripheral item, an effect was detected for the context from which those items had been drawn. The peripheral original detail was least likely to be reported when it had appeared in the same context as a weapon. Conversely, when the peripheral original detail had appeared in the newspaper scenario, it was more likely to be reported. Since the type of postevent task had little effect on the reporting of the peripheral detail, these findings suggest that factors present at encoding affected memory for the peripheral detail in these scenarios.

The availability of the original peripheral detail also influenced the misinformation effect. Both additive and contradictory misinformation effects were more likely to occur when the original detail was not reported. Specifically, misinformation effects were more likely to occur in relation to the peripheral detail in the weapon scenario than when the peripheral detail was drawn from the newspaper scenario. This increase in misinformation effects for the weapon-peripheral detail was likely due to the poor recognition of the original weapon-peripheral detail. If the weapon-peripheral detail had not been encoded, or had produced a very weak memory, the participants would have been unlikely to remember it at test. Thus, there would have been little competition for retrieval between the original and the misleading details. On the other hand, misinformation effects were less likely to occur for the newspaper-peripheral detail, perhaps because the original detail was remembered better. At test, therefore, the original newspaper-peripheral detail may have been more likely to come to mind than the weapon-peripheral detail.

The present findings have implications for real eyewitness behavior. Previous research examining the weapon focus effect has suggested that central details in weapon- present situations are remembered well, in comparison with peripheral details (Pickel et al., 2006). This weapon focus effect suggests that real eyewitnesses may be less likely to remember peripheral details in comparison with weapon-related information and that, therefore, their memory for central details may be more accurate. The present findings, however, suggest that central details are not always remembered accurately and that police questioning may induce forgetting for nonretrieved details and, therefore, leave memory vulnerable to misinformation.

The initiation of retrieval-induced forgetting by police questioning remains a very real possibility. As has been discussed elsewhere (M. D. MacLeod, Saunders, \& Chalmers, in press), police questioning is likely to be incomplete in nature. Since the interviewer was not present during a criminal event, it is unlikely that every aspect of an event will be queried about. Thus, it remains a possibility that details from a criminal event will not be retrieved. The present research also suggests that where retrieval-induced forgetting exists, there is the possibility that misinformation will be incorporated into memory. Thus, incomplete PEQ can lead to errors of both omission (i.e., retrievalinduced forgetting) and commission (i.e., misinformation effects), especially for central details.

The findings from the present experiments suggest that postevent factors, such as incomplete questioning and misleading information, can affect memory for weaponpresent and weapon-absent scenes. Despite memory for central details being strong, memory for these items can be influenced by postevent factors, suggesting that information that is deemed to be central to a scenario does not necessarily indicate reliability of memory. Peripheral information also appears to be affected by postevent misleading information, although the mechanism by which misinformation effects occur may differ from that found for central details. For these items, poor encoding may be the primary route to misinformation effects. Thus, although weapon focus research tends to highlight the problems of reliability concerning peripheral details, it may be the case that memory for central items is also fallible.

\section{AUTHOR NOTE}

Correspondence concerning this article should be addressed to J. Saunders, Psychology Department, Swansea University, Singleton Park, Swansea SA2 8PP, Wales (e-mail: j.saunders@swan.ac.uk).

\section{REFERENCES}

Anderson, M.C. (2003). Rethinking interference theory: Executive control and the mechanisms of forgetting. Journal of Memory \& Language, 49, 415-445.

Anderson, M. C., BJork, E. L., \& BJork, R. A. (2000). Retrievalinduced forgetting: Evidence for a recall-specific mechanism. Psychonomic Bulletin \& Review, 7, 522-530.

Anderson, M. C., BJork, R. A., \& BJork, E. L. (1994). Remembering can cause forgetting: Retrieval dynamics in long-term memory. Journal of Experimental Psychology: Learning, Memory, \& Cognition, 20, 1063-1087.

BeKerian, D. A., \& Bowers, J. M. (1983). Eyewitness testimony: Were we misled? Journal of Experimental Psychology: Learning, Memory, \& Cognition, 9, 139-145.

Christianson, S.-A. (1992). Emotional stress and eyewitness memory: A critical review. Psychological Bulletin, 112, 284-309. 
EAsterbrook, J. A. (1959). The effect of emotion on cue utilization and the organization of behavior. Psychological Review, 66, 183-201.

Echterhoff, G., Groll, S., \& Hirst, W. (2007). Tainted truth: Overcorrection for misinformation influence on eyewitness memory. Social Cognition, 25, 367-409.

Frost, P. (2000). The quality of false memory over time: Is memory for misinformation "remembered" or "known"? Psychonomic Bulletin \& Review, 7, 531-536.

Hauer, B. J. A., Wessel, I., Merckelbach, H., Roefs, A., \& DalGLEISH, T. (2007). Effects of repeated retrieval of central and peripheral details in complex emotional slides. Memory, 15, 435-449.

Kramer, T. H., Buckhout, R., \& Eugenio, P. (1990). Weapon focus, arousal, and eyewitness memory: Attention must be paid. Law \& Human Behavior, 14, 167-184.

LANDAuer, T. K., \& BJORK, R. A. (1978). Optimum rehearsal patterns and name learning. In M. M. Grunneberg, R. E. Morris, \& R. N. Sykes (Eds.), Practical aspects of memory (pp. 625-632). London: Academic Press.

LINDSAY, D. S. (1990). Misleading suggestions can impair eyewitnesses' ability to remember event details. Journal of Experimental Psychology: Learning, Memory, \& Cognition, 16, 1077-1083.

LindSAY, D. S., \& JoHnson, M. K. (1989). The eyewitness suggestibility effect and memory source. Memory \& Cognition, 17, 349-358.

LofTus, E. F. (2005). A 30-year investigation of the malleability of memory. Learning \& Memory, 12, 361-366.

Loftus, E. F., \& Hoffman, H. G. (1989). Misinformation and memory: The creation of new memories. Journal of Experimental Psychology: General, 118, 100-104.

Loftus, E. F., Loftus, G. R., \& Messo, J. (1987). Some facts about weapon focus. Law \& Human Behavior, 11, 55-62.

Loftus, E. F., Miller, D., \& Burns, H. (1978). Semantic integration of verbal information into a visual memory. Journal of Experimental Psychology: Human Learning \& Memory, 4, 19-31.

MacLeod, C. M., Dodd, M. D., Sheard, E. D., Wilson, D. E., \& BIBI, U. (2003). In opposition to inhibition. In B. H. Ross (Ed.), The psychology of learning and motivation: Advance in research and theory (Vol. 43, pp. 163-214). San Diego: Academic Press.

MacLeOD, M. D. (2002). Retrieval-induced forgetting in eyewitness memory: Forgetting as a consequence of remembering. Applied Cognitive Psychology, 16, 135-149.

MacLeod, M. D., \& Anderson, M. C. (2008). Can guided retrieval practice promote misinformation effects? Exploring the role of retrieval-induced forgetting in the misinformation paradigm. Manuscript in preparation.

MacLeod, M. D., \& SAunders, J. (2005). The role of inhibitory control in the production of misinformation effects. Journal of Experimental Psychology: Learning, Memory, \& Cognition, 31, 964-979.

MACLEOD, M. D., \& SAUnders, J. (2006). Forgetting as a consequence of remembering: Retrieval-induced forgetting and the malleability of memory. In A. M. Columbus (Ed.), Advances in psychology research (Vol. 44, pp. 113-135). New York: Nova Science.
MacLeod, M. D., \& SAUnders, J. (2008). Negative consequences of an adaptive process: Retrieval inhibition and memory distortion. Current Directions in Psychological Science, 17, 26-30.

MacLeod, M. D., Saunders, J., \& Chalmers, L. (in press). Updating memory: The unintended consequences of unintended forgetting. In G. M. Davies \& D. Wright (Eds.), New frontiers in applied memory.

McCloskey, M., \& Zaragoza, M. (1985). Misleading postevent information and memory for events: Arguments and evidence against memory impairment hypotheses. Journal of Experimental Psychology: General, 114, 1-16.

Morris, P. E., \& FriTz, C. O. (2000). The name game: Using retrieval practice to improve the learning of names. Journal of Experimental Psychology: Applied, 6, 124-129.

Morris, P. E., \& Fritz, C. O. (2002). The improved name game: Better use of expanding retrieval practice. Memory, 10, 259-266.

PICKEL, K. L. (1998). Unusualness and threat as possible causes of "weapon focus." Memory, 6, 277-295.

PICKEL, K. L. (1999). The influence of context on the "weapon focus" effect. Law \& Human Behavior, 23, 299-311.

PICKEL, K. L. (2007). Remembering and identifying menacing perpetrators: Exposure to violence and the weapon focus effect. In R. C. L. Lindsay, D. F. Ross, J. D. Read, \& M. P. Toglia (Eds.), The handbook of eyewitness psychology: Vol. 2. Memory for people (pp. 339-360). Mahwah, NJ: Erlbaum.

Pickel, K. L., Ross, S. J., \& Truelove, R. S. (2006). Do weapons automatically capture attention? Applied Cognitive Psychology, 20, 871-893.

Racsmany, M., \& Conway, M. A. (2006). Episodic inhibition. Journal of Experimental Psychology: Learning, Memory, \& Cognition, 32, 44-57.

Rojahn, K., \& Pettigrew, T. F. (1992). Memory for schema-relevant information: A metaanalytic resolution. British Journal of Social Psychology, 31, 81-109.

Saunders, J., \& MaCLeOd, M. D. (2002). New evidence on the suggestibility of memory: The role of retrieval-induced forgetting in misinformation effects. Journal of Experimental Psychology: Applied, 8, 127-142.

ShaW, J. S., III, BJork, R. A., \& Handal, A. (1995). Retrieval-induced forgetting in an eyewitness-memory paradigm. Psychonomic Bulletin \& Review, 2, 249-253.

Wright, D. B., \& Stroud, J. N. (1998). Memory quality and misinformation for peripheral and central objects. Legal \& Criminological Psychology, 3, 273-286.

Zaragoza, M. S., \& Lane, S. M. (1994). Source misattributions and the suggestibility of eyewitness memory. Journal of Experimental Psychology: Learning, Memory, \& Cognition, 20, 934-945.

Manuscript received August 7, 2008; revision accepted for publication December 4, 2008.) 